\title{
EVIDENCIAÇÃO DOS ATIVOS INTANGÍVEIS DAS EMPRESAS LISTADAS NO NOVO MERCADO DA B3 EM CONFORMIDADE COM CPC 04 (R1)
}

\section{EVIDENCE OF INTANGIBLE ASSETS OF COMPANIES LISTED ON B3'S NEW MARKET IN ACCORDANCE WITH CPC 04 (R1)}

\section{CRISTIANE LINS DA ROSA DIONIZIO}

Especialista em Gestão Contábil Financeira - UTFPR

Universidade Tecnológica Federal do Paraná - UTFPR

Orcid: https://orcid.org/0000-0003-3622-851X / E-mail: crislinsrosa23@gmail.com

\section{LUCIANE DAGOSTINI}

Doutoranda do PPGCONT - UFPR

Docente do curso de Ciências Contábeis - Universidade Tecnológica Federal do Paraná - UTFPR Endereço: Via do Conhecimento, Km 1 - Pato Branco - PR, CEP 85503-390 - Telefone: (046)32202511 Orcid: https://orcid.org/0000-0002-9351-8778 / E-mail: lu.dagostini2020@gmail.com

\section{NAYANE THAIS KRESPI MUSIAL}

Doutora em Métodos Numéricos em Engenharia - UFPR Universidade Federal do Paraná - UFPR

Orcid: https://orcid.org/0000-0002-9653-1417 / E-mail: nkrespi@gmail.com /

\section{RESUMO}

O presente estudo teve como objetivo verificar o nível de evidenciação dos ativos intangíveis das empresas listadas no segmento Novo Mercado da B3, em conformidade com o disposto no CPC 04 (R1), no ano de 2017. A coleta dos dados deu-se por meio de um checklist embasado no CPC 04, adaptado do estudo de Moura, Varela e Beuren, (2014). A metodologia caracterizase quanto ao objetivo como descritiva, quanto aos procedimentos como documental e a abordagem do problema como uma análise quali-quantitativa. Os resultados revelaram um índice de evidenciação médio de conformidade de 70,61\%, sendo que o maior índice obtido pelas empresas analisadas foi de $87,50 \%$ pela empresa Ecorodovias e o menor índice de 4,76\% pelas empresas Direcional e Even Construtora. Na análise realizada por setor, constatou-se que o setor com maior índice de evidenciação foi o setor de Bens Industriais, obtendo um percentual de $80,48 \%$ e o setor que menos evidenciou foi o setor de Materiais Básicos com um percentual de 58,33\%. Por fim, verificou-se que o nível de evidenciação dos ativos intangíveis das empresas listadas no segmento Novo Mercado da B3 considerado alto foi de $53,45 \%$, evidenciando mais de $75 \%$ dos itens analisados. Também, verificou-se que $35,54 \%$ das empresas estão em um nível de evidenciação considerado médio/alto e que aproximadamente $12 \%$ das empresas estão em um nível considerado baixo ou médio/baixo. Ou seja, mais da metade das empresas tem se adequado e melhorado suas divulgações em conformidade as normas estabelecidas pelo CPC 04 (R1), (2011).

Palavras-chave : Evidenciação. Ativos Intangíveis. CPC 04 (R1). 


\begin{abstract}
The present study aimed to verify the level of evidence of intangible assets of companies listed in the Novo Mercado segment of B3, in accordance with the provisions of CPC 04 (R1), in 2017. Data collection was carried out through from a checklist based on CPC 04, adapted from the study by Moura, Varela and Beuren, (2014). A methodology consists of the descriptive objective, the documentary procedures, and the approach to the problem as a qualiquantitative analysis. The results revealed an average evidence of conformity index of $70.61 \%$, with the highest index by the companies analyzed $87.50 \%$ by the company Ecorodovias and the lowest index of $4.76 \%$ by the companies Direcional and Even Construtora. In the analysis carried out by sector, it was found that the sector with the highest evidence index was the Industrial Goods sector, obtaining a percentage of $80.48 \%$ and the sector that least evidenced was the Basic Materials sector with a percentage of 58, 33\% Finally, it was found that the level of evidence of the intangible assets of companies listed in the Novo Mercado segment of B3 considered high was $53.45 \%$, evidencing more than $75 \%$ of the items analyzed. Also, it was found that $35.54 \%$ of companies are at a level of evidence considered medium / high and that approximately $12 \%$ of companies are at a level considered low or medium / low. In other words, more than half of the companies have adequacy and improved their disclosures in accordance with the rules applicable by CPC 04 (R1), (2011).
\end{abstract}

Keywords: Disclosure. Intangible assets. CPC 04 (R1).

\title{
1 INTRODUÇÃO
}

O desenvolvimento econômico e a concorrência de mercados fazem com que as empresas não se limitem a fatores tradicionais, como capital e trabalho, mas que busquem por diferenciais para manterem-se competitivas no mercado. A consequência disto reflete em uma mudança de evidenciação de ativos nas demonstrações das empresas, que até então eram predominantemente ativos tangíveis, passando então a registrar os ativos intangíveis que fazem parte de suas atividades, ou que são produzidos internamente (MOURA; THEISS; CUNHA, 2014).

Neste sentido, os ativos intangíveis estão ganhando frente aos ativos tangíveis por serem considerados como um potencial de competitividade empresarial, além de que, seu reconhecimento e mensuração reflete aos investidores que empresa tem noção de seu devido valor e melhorando a qualidade da informação contábil disponibilizada aos usuários. Também deve se levar em consideração que em algumas empresas o montante de ativos intangíveis está crescendo substancialmente frente aos ativos tangíveis registrados (VISVANATHAN, 2017; LIM; MACIAS; MOELLER, 2019). Fato este que reflete a mudança nas formas tradicionais de operacionalização dos mercados (ANTUNES; LEITE, 2008).

Diante disto, se fez necessária a criação de normas de registro para os ativos intangíveis que atendessem as demandas de evidenciação, mensuração e divulgação destes nas demonstrações contábeis das empresas. Perante este cenário e ao encontro das Normas Internacionais de Contabilidade, no ano de 2008 foi criado o Pronunciamento Técnico CPC 04 2010 - Ativos Intangíveis, embasado pela IAS 38. Este CPC tem por objetivo definir o tratamento contábil dado aos ativos intangíveis e determinar os critérios para reconhecimento destes ativos estabelecendo como deve ser feita sua evidenciação, mensuração e divulgação (SILVA; FERREIRA; MARAGNO, 2017).

RGO - Revista Gestão Organizacional, Chapecó, v. 13, n. 2, p. 142-161, maio/ago. 2020. 
Existe uma preocupação constante quanto a evidenciação dos ativos intangíveis por parte das empresas, devido à sua relevância, forma de mensuração e de evidenciação. Ou seja, no sentido de como retratar com fidelidade e segurança os ativos intangíveis nas demonstrações contábeis, representando um desafio tanto para os contadores quanto para os gestores fazerem as escolhas contábeis pertinentes para o registro. Neste sentido, em virtude do enredamento que envolve o reconhecimento e mensuração dos ativos intangíveis, pode ocorrer a divulgação de informação contábil viesada para os usuários e interferir também na valoração da empresa (DOMENEGHETTI; MEIER, 2009).

Eloy e Souza (2018) reportam a preocupação quanto a correta evidenciação dos ativos intangíveis. Destacam que a maioria das entidades listadas, que divulgam suas demonstrações nas bolsas de valores, vem demonstrando uma relevante diferença entre seu valor contábil e seu valor econômico. Que de fato esta diferença está atrelada a importância dos ativos intangíveis na constituição patrimonial das empresas.

Essa relação entre o valor de mercado e o valor contábil, para Moraes e Carvalho (2017) origina o que se chama de grau de intangibilidade, índice que está cada vez mais associado aos resultados financeiros das companhias. Logo, a admissão do ativo intangível nas análises econômicas oferece benefícios, já que os valores apresentados pela contabilidade não demonstram a verdadeira representatividade de uma empresa no mercado atual.

Silva, Ferreira e Maragno (2017), reportam que os ativos intangíveis impactam diretamente nos resultados das empresas, mesmo que raro este reconhecimento, já que afetam diretamente nos lucros das entidades, pois criam valor de forma isolada e o agrupamento destes ativos é essencial para a geração de valor deles. Labidi e Gajewski (2019) corroboram que as empresas divulgam informações insuficientes sobre os ativos intangíveis e que aumentariam sua liquidez quando fazem ofertas de ações se aumentassem a evidenciação dos ativos intangíveis.

Por conseguinte, tendo em vista a evolução da convergência contábil das normas brasileiras às Normas Internacionais de Contabilidade e a importância da evidenciação dos ativos intangíveis para as empresas, o presente artigo traz como problema de pesquisa: Como as empresas listadas no segmento Novo Mercado da B3 evidenciaram seus ativos intangíveis, com base nos critérios estabelecidos pelo CPC 04 (R1) no ano de 2017? Considerando o exposto, o objetivo geral deste artigo é: verificar o nível de evidenciação dos ativos intangíveis das empresas listadas no segmento Novo Mercado da B3, em conformidade com o disposto no CPC 04 (R1).

Isto posto, este estudo se justifica no fato de que as organizações não devem limitarse apenas aos recursos materiais, dado que ativos tangíveis e intangíveis trabalham em atuação conjunta em seu favor, tornando-as mais eficientes. É a união de ambos que influenciará uma alavancagem significativa e positiva nos resultados da empresa, bem como uma melhoria na sua imagem perante seus stakeholders (FREIRE; ALBUQUERQUE FILHO; MACEDO, 2018).

Percebe-se que o esforço das empresas em assimilar, compreender e possuir ativos intangíveis justifica-se por serem considerados um dos principais agentes de geração de valor que pode alavancar o desempenho das empresas (HAJI; GHAZALI, 2018). De acordo com Freire, Albuquerque Filho e Macedo (2018), nota-se a relevância dos ativos intangíveis para as entidades e que há um longo caminho a percorrer no que se refere a identificação e mensuração desses ativos.

Também é preciso consideram que as empresas de capital aberto são reguladas pela Comissão de Valores Mobiliários (CVM), que aprovou a Deliberação no 644 em 02 de 
dezembro de 2010, aprovando o Pronunciamento Técnico CPC 04 (R1) do Comitê de Pronunciamentos Contábeis - CPC sobre ativo intangível. Tornando assim obrigatório que as empresas a ela subordinadas atendam aos critérios estabelecidos em relação as operações que envolvam ativos intangíveis. Ora pois, estas empresas serão auditadas quanto à adequação das demonstrações contábeis em obediência as Normas de Contabilidade vigentes, reforçando assim a importância do registro dos ativos intangíveis da forma mais adequada e consoante a legislação pertinente.

Com efeito muito tem se estudado sobre este tema nos últimos anos no intuito de apurar os avanços no processo de divulgação das informações sobre os ativos intangíveis. Dentre estas pesquisas mais recentes realizadas sobre os ativos intangíveis com o uso de checklists quer sejam adaptados do CPC 04 (R1) ou IAS 38, neles os pesquisadores buscaram conhecer o nível de evidenciação das companhias abertas brasileiras listadas na B3, tais como: Moura, Varella e Beuren (2014), Lopes et al., (2014), Silva Filho et al., (2014), Brizolla e Turra (2015), Oro e Klann (2015), Lima et al., (2015), Magro et al., (2017), Mello et al., (2017), Cavalcanti et al., (2017), Ritta, Cunha e Klann (2017), Ventura e Rover (2017), Silva, Ferreira e Maragno, (2017), Almeida e Jordão (2017), Barsch e Souza (2018), Callado e Silva (2018), Joseph et al., (2018), Freire, Albuquerque Filho e Macedo (2018), Piontkewicz e Freitas (2018) Labidi e Gajewski, (2019), Sharma e Kaur, (2019). Concluíram que apesar de nenhuma empresa ter atingido 100\% a aderência ao disposto no CPC 04 (R1), há uma evolução do índice de evidenciação dos ativos intangíveis por parte destas empresas.

Ainda destacam-se outras pesquisas relacionadas com ativos intangíveis, porém associadas a outras temáticas como: grau de intangibilidade (RITTA; CUNHA; KLANN, 2017; FREIRE; ALBUQUERQUE FILHO; MACEDO, 2018), vida útil, amortização e Impairment Test (MOURA et al., 2011; ORO; KLANN, 2015), ativos intangíveis e variáveis de Governança Corporativa (MOURA; VARELLA; BEUREN, 2014; ELOY; SOUZA, 2018; FREIRE; ALBUQUERQUE FILHO; MACEDO, 2018), grau de intangibilidade e variáveis de desempenho financeiro (PUNTILLO, 2009; MENESES; PONTE; MAPURUNGA, 2011; JANOSEVIÆ; DZENOPOLAC, 2012; BRIZOLLA; TURRA, 2015; MORAES; CARVALHO, 2017; RITTA; CUNHA; KLANN, 2017; HAJI; GHAZALI, 2018), endividamento e nível de risco (KAYO, 2002), com auditoria (MUHAMMADI; AHMED; HABIB, 2016), honorários de auditoria (VISVANATHAN, 2017) e estrutura de capital (LIM; MACIAS; MOELLER, 2019).

\section{REFERENCIAL TEÓRICO}

\subsection{ATIVOS INTANGÍVEIS: RECONHECIMENTO, MENSURAÇÃO E EVIDENCIAÇÃO}

Por definição de acordo com o Pronunciamento Técnico CPC 00 (R2) (2019, pg. 19), "ativo é um recurso econômico presente controlado pela entidade como resultado de eventos passados, estes ainda podem ser classificados como tangível e intangível". A lei 11.638/2007 traz como definição que os ativos intangíveis são direitos que tenham por objeto bens incorpóreos que sejam destinados à manutenção da entidade, ou desempenhado com este intuito.

Neste sentido, o CPC 04 (R1) (2011), que foi transcrito do IAS 38 (Intangible Assets 38), define que ativos intangíveis são aqueles ativos não monetários, identificáveis, que não possuem substância física, que são controláveis e geradores de benefícios econômicos futuros. Quando um ativo intangível não atender a definição dada pelo CPC 04 (R1) (2011), 
todos os gastos incorridos para a sua aquisição e/ou geração deve ser reconhecido como despesa sempre que existir.

Meneses, Ponte e Mapurunga (2013) estabelecem ainda que o toque pode ser a característica que distingue os ativos tangíveis dos intangíveis. Logo, os ativos tangíveis são aqueles que fazem parte do patrimônio da empresa, que são palpáveis, ou seja, são constituídos por imóveis, terrenos, máquinas, dentre outros de substância física. Ao passo que os intangíveis se referem aos bens que não se pode tocar, nem se pode perceber. Portanto, podem constituir-se por marcas, patentes, capacidade de inovação, capital humano e afins (SILVA; FERREIRA; MARAGNO, 2017).

O CPC 04 (R1) (2011) define ainda que os ativos intangíveis precisam atender aos critérios de reconhecimento, mensuração e evidenciação. Para ser reconhecido como um ativo intangível é preciso que sejam provados que seus benefícios econômicos futuros esperados e atribuíveis aos mesmos serão gerados em favor da entidade, além de seu custo ser mensurado com confiabilidade. Barcelos et al., (2011) citam que os benefícios econômicos futuros gerados pelos ativos intangíveis podem advir por meio de uma receita de venda de produtos ou serviços, redução de custos ou outros benefícios resultantes do uso do ativo pela entidade.

Já, para que um ativo intangível seja mensurado, se faz necessário avaliar a possibilidade de estimativa segura do ativo e definir e o método de amortização utilizado (LEMES; CARVALHO, 2010). Quanto a forma de mensuração, de acordo com o que determina o CPC 04 (R1) (2011) está previsto que a entidade pode, em determinadas circunstâncias, escolher entre mensurar pelo método de custo ou pelo método de reavaliação. Contudo, ao optar pelo método de reavaliação terá que verificar se não há nenhuma restrição legal préestabelecida que venha impedir esta escolha.

Deste modo, após o seu reconhecimento inicial o mesmo deve ser apresentado pelo seu custo, sendo assim desconsiderada uma eventual amortização acumulada e alguma perda acumulada. Para o método de reavaliação, após o seu reconhecimento inicial, se permitido legalmente, um ativo intangível pode ser apresentado pelo seu valor reavaliado, consonante ao seu valor justo à data da reavaliação. No que tange a reavaliação nos termos do Pronunciamento Técnico, o valor justo deve ser mensurado em relação a um mercado ativo, lembrando que a reavaliação deve ser realizada frequentemente para que na data do balanço não venha a apresentar divergências significativas em relação ao seu valor justo (CPC 04 (R1), 2011).

Para evidenciar os ativos intangíveis de modo a atender a normativa dada pelo CPC 04 (R1) (2011), se faz necessário algumas informações relacionadas aos ativos intangíveis, como o método de amortização utilizado, o montante da amortização e do valor contábil bruto, se a vida útil são indefinidas ou finitas, e se forem infinitas deve ser informado qual o método de estimação adotado (LEMES; CARVALHO, 2010). Ainda, os critérios que serão utilizados nesta pesquisa são oriundos do que estabelece o CPC 04 (R1) para a evidenciação dos ativos intangíveis (Quadro 2). Em que a entidade precisa atender a quesitos referentes a vida útil/valor, amortização, adições e baixas, além de informação sobre toda e qualquer reavaliação realizada pertinentes aos ativos intangíveis.

A evidenciação propicia que as empresas demonstrem aos seus mais diversos usuários que os ativos intangíveis oferecem diferenciação no mercado atual por trazer vantagens competitivas, visto que se reconhece a devida relevância dos ativos intangíveis para a condução dos negócios como fonte de subsidiar o desempenho organizacional das entidades 
(RITTA; CUNHA; KLANN, 2017). Neste contexto, O Quadro 1, apresenta quais são os ativos intangíveis mais usualmente reconhecidos nas demonstrações contábeis:

Quadro 1 - Exemplos de Ativos Intangíveis

\begin{tabular}{|c|c|}
\hline Tipo & Características \\
\hline Marca & $\begin{array}{l}\text { Símbolo, termo ou nome que identifica um produto ou } \\
\text { empreendimento comercialmente. }\end{array}$ \\
\hline Títulos de periódicos & $\begin{array}{c}\text { São publicações eletrônicas e/ou impressas, que ocorrem em } \\
\text { determinados intervalos de tempo. }\end{array}$ \\
\hline Software (sistema computacional) & $\begin{array}{c}\text { Sistema lógico que processa dados de acordo com instruções } \\
\text { programadas. }\end{array}$ \\
\hline Licenças e franquias & $\begin{array}{l}\text { Direito concedido a terceiros, para o uso comercial de produtos e } \\
\text { serviços ou exploração de recursos naturais ou públicos. }\end{array}$ \\
\hline $\begin{array}{l}\text { Direitos autorais, concessões, } \\
\text { patentes e outros direitos de } \\
\text { propriedade }\end{array}$ & $\begin{array}{c}\text { Direito passível de controle e exploração industrial, operacional ou } \\
\text { de serviço que gera benefícios incrementais futuros. }\end{array}$ \\
\hline $\begin{array}{l}\text { Receitas, fórmulas, modelos, projetos } \\
\text { e protótipos }\end{array}$ & $\begin{array}{l}\text { São elementos controlados pela empresa capazes de gerar } \\
\text { benefícios futuros. }\end{array}$ \\
\hline $\begin{array}{l}\text { Ativos Intangíveis em } \\
\text { desenvolvimento }\end{array}$ & $\begin{array}{l}\text { Gastos incorridos que possuem capacidade de benefícios futuros, } \\
\text { na geração de novos conhecimentos, produtos ou serviços. }\end{array}$ \\
\hline $\begin{array}{l}\text { Goodwill (Ágio por expectativa de } \\
\text { rentabilidade futura) }\end{array}$ & $\begin{array}{c}\text { Compra vantajosa de uma combinação de negócios, ágio por } \\
\text { expectativa de rentabilidade futura. }\end{array}$ \\
\hline
\end{tabular}

Fonte: Ritta, Cunha e Klann (2017)

As constantes mudanças no ambiente empresarial e no cenário mundial em razão da globalização, tem levado as empresas a investirem mais nas áreas de informação, pesquisa e conhecimento, fato que elevou os ativos intangíveis a outro patamar de importância nas entidades. Além disto, foram incorporados nas atividades das empresas, sejam como objeto de negociação (exemplo: licenças e franquias) ou como necessários para as atividades operacionais (exemplo: licenças de softwares). Fazendo com que aquelas que melhor gerenciarem seus intangíveis alcançarão maior competividade no mercado atual. Ainda, em alguns casos os ativos intangíveis chegam a ser mais importantes e significativos para as empresas do que as máquinas, móveis e imóveis, pois passaram a ser necessários no atual contexto de desenvolvimento tecnológico e mercadológico (PINTO, 2017; VISVANATHAN , 2017; LIM; MACIAS; MOELLER, 2019).

Chander e Mehra (2011), destacam como em diferentes partes do mundo este tema é de fato relevante e mostraram como vem sendo estudado, visando examinar a extensão dos relatórios dos ativos intangíveis, além de retratarem como o processo de criação de valor tornaram-se importantes para as empresas, pois reconhecendo-os se faz necessária a sua comunicação aos interessados como acionistas, investidores, etc.

\subsection{ESTUDOS PRECEDENTES}

Uma vez que é relevante um estudo aprofundado sobre o tema, a seguir são relacionadas diferentes pesquisas, destacando suas contribuições e resultados, que foram utilizados como base para o presente estudo.

Os estudos que analisaram a evidenciação dos ativos intangíveis com uso de checklist relacionado ao CPC 04 (R1), são: Antunes, Da Silva e Saiki (2009), Crisóstomo, (2009), Ritta, Ensslin e Ronchi, (2010), Barcellos et al., (2011), Marques, Santos e Gouveia, (2011), Jacques, Rasia e Ott, (2012), Santos et al., (2012), Moura e Varela, (2014), Lopes et al., (2014), Lima et al., (2015), Silva, Ferreira e Maragno, (2017). 
Os estudos anteriores sobre os ativos intangíveis com o uso de checklists, quer sejam adaptados do CPC 04 ou da IAS 38, neles os pesquisadores buscaram conhecer o nível de evidenciação das companhias abertas brasileiras listadas na B3, concluíram que apesar de nenhuma empresa ter atingido $100 \%$ a aderência ao disposto no CPC 04, identifica-se que há uma saudável intenção em adequar-se ao que determina o Pronunciamento Técnico.

Demonstraram ainda que no período analisado o ágio, software e os direitos contratuais foram os elementos de ativos intangíveis mais evidenciados pelas empresas, também concluíram que as alterações mais significativas ocorreram no final do exercício de 2008, evidenciando ainda mais a real inclinação em adaptar-se à nova realidade imposta.

Verificaram também que as empresas analisadas ao divulgarem suas informações sobre os ativos intangíveis em suas demonstrações contábeis tiveram como canal mais utilizado as notas explicativas, indicando uma sintonia com o que determina o CPC 04 (R1) (2011), demonstrando que este tornou-se de fato eficaz em sua aplicação. E, no que tange a divulgação simultânea de ativos intangíveis e imobilizados, a conclusão foi que na população analisada nenhuma das empresas divulgou de forma completa as informações referentes aos ativos intangíveis e imobilizados simultaneamente, apontando que apesar da boa intenção em adaptar-se ainda existe certa dificuldade para cumprir integralmente as normas determinadas pela nova legislação vigente.

Da mesma forma que Labidi e Gajewski (2019) identificaram que as empresas francesas aumentariam sua liquidez do mercado de ações em torno de novas ofertas de ações se aumentassem o índice de divulgação dos ativos intangíveis, identificando que as empresas evidenciam informações insuficientes sobre os ativos intangíveis. Sharma e Kaur (2019) analisaram a evidenciação dos ativos intangíveis em empresas indianas, constatando aumento em determinado período e declínio no percentual de evidenciação no período seguinte. Constataram também que o setor de cuidados pessoais e de saúde e telecomunicações são mais precisos na evidenciação dos ativos intangíveis.

Há também outras pesquisas que relacionaram os ativos intangíveis com outras variáveis, sem o uso do checklist do CPC 04 (R1), destacando assim a importância da evidenciação dos ativos intangíveis a influência destes no contexto das organizações. Como: endividamento e nível de risco (KAYO, 2002), capital intelectual, desempenho financeiro, criação de valor (PUNTILLO, 2009), Tamanho e status (CUNHA et al., 2011), valor do intangível, amortização, vida útil, conciliação do valor contábil (MOURA et al., 2011), tamanho, lucro, rentabilidade e endividamento das empresas (MENESES; PONTE; MAPURUNGA, 2013), valor de mercado e valor contábil das empresas (SAHUT; BOULERNE; TEULON, 2011), origem, representatividade (RECH; SCHNORRENBERGER; LUNKES, 2012), Value Added Intelectual Coefficient (VAICTM), Eficiência de Capital Humano (HCE), Eficiência Capital Estrutural (SCE) e Capital Eficiência Empregado (CEE) (BRIZOLLA; TURRA, 2015), taxas de depreciação (FREIRE et al., 2012), goodwil (SILVA FILHO, 2012; ELOY; SOUZA, 2018), governança corporativa (MOURA; VARELLA; BEUREN, 2014; FREIRE; ALBUQUERQUE FILHO; MACEDO, 2018), Impairment Test (ORO; KLANN, 2015), retorno de ações (MAGRO et al., 2017), Q de Tobin, Grau de intangibilidade, EVA, SPREAD, ROA, ROE, ROI (JANOSEVIAE; DZENOPOLAC, 2012; MORAES; CARVALHO, 2017; RITTA; CUNHA; KLANN, 2017).

No contexto internacional, Haji e Ghazali (2018) pesquisaram o papel dos ativos e passivos intangíveis no desempenho das empresas na Malásia, os resultados evidenciam que os ativos intangíveis têm impacto positivo no desempenho das empresas, enquanto os passivos intangíveis apresentaram impacto negativo. Muhammadi, Ahmed e Habib (2016) pesquisaram as dificuldades enfrentadas pelos auditores fiscais da Indonésia para auditar os 
preços de transferência multinacionais de ativos intangíveis. Constataram dificuldades como falta de transparência, cooperação limitada em fornecimento de documentos, regulamentação, falta de organização e pessoal. Lim, Macias e Moeller (2019) verificaram a relação entre ativos intangíveis e alavancagem financeira em empresas dos EUA. Evidenciaram que tanto ativos intangíveis quanto tangíveis são significativos na estrutura de capital, denotando a necessidade de distinção destes. Visvanathan (2017) estudou como os auditores veem os ativos intangíveis registrados em empresas dos EUA, identificando que os auditores cobram maiores honorários de auditoria de empresas com maior proporção de ativos intangíveis registrados.

No âmbito de pesquisas bibliográficas e análises empíricas, destacam-se os estudos bibliográficos de Caldas e Carvalhal (2011); Gerhardt e Siluk, (2017); Callado e Silva, (2018); Joseph et al., (2018). As pesquisas empíricas de Moura, Fank e Rausch, (2014); Sgoda e Freitag, (2015); Mello et al., (2017); Cavalcanti et al., (2017); Mello (2017).

Neste contexto, fica evidenciada a importância dada pela literatura em relação a temática dos ativos intangíveis. Pois, mesmo com a seriedade dada pelas empresas para evidenciar os ativos intangíveis, em muitas situações a norma permite que se façam escolhas contábeis ou ainda não deixa explícita a metodologia a ser desenvolvida para a correta evidenciação. Além disto, é preciso lembrar que o usuário da informação contábil precisa de consistência contábil e legibilidade de informação para melhor interpretar a evolução das contas. Considerando também a necessidade cumprimento de normas estabelecidas por órgãos reguladores que situam que seja feita a evidenciação. $E$, nesta pesquisa tem-se como objetivo verificar se as empresas listadas no segmento do Novo Mercado estão evidenciando os ativos intangíveis em suas demonstrações contábeis, visto que os estudos precedentes evidenciaram um aumento de evidenciação dos ativos intangíveis, porém ainda não atendem a totalidade da evidenciação.

\section{PROCEDIMENTOS METODOLÓGICOS}

O delineamento metodológico fundamenta-se quanto ao seu objetivo como descritivo, com a abordagem quali-quantitativa. Pois, tanto qualifica, quanto quantifica analisando as informações sobre ativos intangíveis demonstrados nos relatórios financeiros e notas explicativas das empresas analisadas, verificando se estão em concordância ao que o Pronunciamento Técnico CPC 04 (R1). O procedimento é classificado documental, utilizandose de dados secundários, porquanto foram obtidos por meio de análise dos documentos divulgados na B3, tais como balanço patrimonial consolidado, notas explicativas e dados obtidos nos websites das empresas da amostra.

Para obter a amostra final da pesquisa, a população inicial era composta pelas 120 empresas listadas na B3, no ano de 2017, do segmento Novo Mercado e que apresentaram suas demonstrações contábeis referentes ao exercício social de 2017 até o mês de março do 2018. Contudo a amostra final foi reduzida para 116 empresas, sendo esta redução ocorreu devido ao fato de algumas empresas apresentarem suas demonstrações em dois setores/subsetores, motivo pelo qual aparecem duas vezes na relação, ou ainda por não terem apresentado os dados solicitados no checklist ou estão em recuperação judicial invalidando suas apresentações por estarem incompletas.

Para a coleta de dados foi utilizado um checklist, de perguntas adaptado do estudo de Moura, Varela e Beuren (2014). Com intuito de obter dados que mostrem informações quanto 
à natureza, a evidenciação, mensuração, a contabilização e a evidenciação dos ativos intangíveis, com base nos dispositivos do CPC 04 (R1), conforme Quadro 2.

Quadro 2: Checklist

\begin{tabular}{|c|c|c|}
\hline $\begin{array}{c}\text { Contexto de } \\
\text { avaliação }\end{array}$ & & Perguntas para identificar o nível de evidenciação dos ativos intangíveis \\
\hline \multirow{9}{*}{$\begin{array}{l}\text { Vida útil } \\
\text { / valor }\end{array}$} & 1 & Divulgou informações sobre intangíveis separados em classes? \\
\hline & 2 & Divulgou se os intangíveis são de vida útil definida ou indefinida? \\
\hline & 3 & $\begin{array}{l}\text { Divulgou os motivos que fundamentam e os fatores mais importantes que levaram à } \\
\text { definição da vida útil definida ou indefinida do intangível? }\end{array}$ \\
\hline & 4 & Divulgou informações sobre os prazos de vida útil ou as taxas de amortização utilizadas? \\
\hline & 5 & Divulgou o valor contábil bruto da classe de intangível no início do período? \\
\hline & 6 & Divulgou o valor contábil bruto da classe de intangível no final do período? \\
\hline & 7 & Divulgou o valor contábil de ativos intangíveis cuja titularidade é restrita? \\
\hline & 8 & Divulgou o valor contábil de ativos intangíveis oferecidos como garantia de obrigações? \\
\hline & 9 & $\begin{array}{l}\text { Divulgou o valor dos compromissos contratuais advindos da aquisição de ativos } \\
\text { intangíveis? }\end{array}$ \\
\hline \multirow{5}{*}{ Amortização } & 10 & Divulgou o valor contábil da amortização acumulada no início do período? \\
\hline & 11 & Divulgou o valor contábil da amortização do período? \\
\hline & 12 & Divulgou o valor contábil da amortização acumulada no final do período? \\
\hline & 13 & $\begin{array}{l}\text { Divulgou os métodos de amortização utilizados para ativos intangíveis com vida útil } \\
\text { definida? }\end{array}$ \\
\hline & 14 & $\begin{array}{l}\text { Divulgou a rubrica da demonstração de resultado em que qualquer amortização de ativo } \\
\text { intangível foi incluída? }\end{array}$ \\
\hline \multirow{5}{*}{$\begin{array}{l}\text { Adições / } \\
\text { baixas }\end{array}$} & 15 & $\begin{array}{l}\text { Divulgou de forma separada o valor contábil das adições que foram geradas por } \\
\text { desenvolvimento interno e as adquiridas, bem como as adquiridas por meio de uma } \\
\text { combinação de negócios? }\end{array}$ \\
\hline & 16 & $\begin{array}{l}\text { Divulgou o valor justo inicialmente reconhecido dos ativos intangíveis adquiridos por } \\
\text { meio de subvenção ou assistência governamentais? }\end{array}$ \\
\hline & 17 & $\begin{array}{l}\text { Divulgou o valor contábil inicialmente reconhecido dos ativos intangíveis adquiridos por } \\
\text { meio de subvenção ou assistência governamentais? }\end{array}$ \\
\hline & 18 & $\begin{array}{l}\text { Divulgou se os ativos intangíveis adquiridos por meio de subvenção ou assistência } \\
\text { governamentais são mensurados, após o reconhecimento, pelo método de custo ou } \\
\text { reavaliação? }\end{array}$ \\
\hline & 19 & $\begin{array}{l}\text { Divulgou o valor contábil dos ativos classificados como mantidos para venda ou incluídos } \\
\text { em grupo de ativos classificados como mantidos para venda e outras baixas? }\end{array}$ \\
\hline \multirow{5}{*}{$\begin{array}{l}\text { Reavaliação/ } \\
\text { teste de } \\
\text { Impairment }\end{array}$} & 20 & Divulgou a data efetiva da reavaliação do intangível? \\
\hline & 21 & $\begin{array}{l}\text { Divulgou o saldo da reavaliação, relacionada aos ativos intangíveis, no início e no final do } \\
\text { período? }\end{array}$ \\
\hline & 22 & $\begin{array}{l}\text { Divulgou informações sobre a realização ou não do teste de Impairment, de acordo com } \\
\text { o Pronunciamento Técnico CPC } 01 \text { - Redução ao Valor Recuperável de Ativos? }\end{array}$ \\
\hline & 23 & $\begin{array}{l}\text { Divulgou o valor das provisões de perdas, reconhecidas no resultado do período, de } \\
\text { acordo com o Pronunciamento Técnico CPC } 01 \text { - Redução ao Valor Recuperável de } \\
\text { Ativos? }\end{array}$ \\
\hline & 24 & $\begin{array}{l}\text { Divulgou o valor das reversões de perdas, reconhecidas no resultado do período, de } \\
\text { acordo com o Pronunciamento Técnico CPC } 01 \text { - Redução ao Valor Recuperável de } \\
\text { Ativos? }\end{array}$ \\
\hline
\end{tabular}

Fonte: Adaptado de Moura, Varela e Beuren (2014).

O checklist adaptado de Moura, Varela, Beuren (2014) utilizado neste estudo, foi elaborado em conformidade com o CPC 04 (R1) (2011). Logo, o Quadro 2 apresenta as 
informações que devem ser divulgadas conforme as orientações do Pronunciamento Técnico CPC 04 (R1) (2011). Por meio deste então buscou-se observar se as informações foram apresentadas conforme as determinações do referido pronunciamento técnico, a análise das notas explicativas ocorreu por meio da sua leitura e busca por palavras-chave relativa aos itens do checklist.

Ao aplicar o checklist, foram atribuídas notas 0 e 1 para cada resposta, sendo a nota 0 para as respostas que não estavam de acordo com as informações obrigatórias em conformidade com o CPC 04 (R1) e nota 1 para as informações divulgadas em conformidade com referido Pronunciamento Técnico. Na sequência, os resultados serão classificados de acordo com Tabela 1, que demonstra o nível de evidenciação classificado em níveis como: baixo, médio/baixo, médio/alto e alto, conforme utilizado por Silva, Ferreira e Maragno (2017).

Tabela 1: Critérios para identificar o nível de evidenciação

\begin{tabular}{c|c}
\hline Pontuação obtida por empresas em\% & Nível de evidenciação \\
\hline \hline 0 a $25 \%$ & Baixo \\
\hline 25,01 a $50 \%$ & Médio/baixo \\
\hline 50,01 a $75 \%$ & Médio/alto \\
\hline 75,01 a $100 \%$ & Alto \\
\hline
\end{tabular}

Fonte: Silva, Ferreira e Maragno (2017)

Deste modo a pontuação final é a soma das 21 respostas pertinentes as 21 perguntas do checklist do Quadro 2. Para averiguar o nível de evidenciação dos ativos intangíveis calculou-se então a proporção dos pontos de cada empresa no tocante ao total de perguntas, conforme Tabela 1, que mostra os critérios tomados para estabelecer o nível de evidenciação.

\section{ANÁLISE DE DADOS}

Nesta parte do estudo, demonstra-se a forma com que os dados foram tratados por meio das análises realizadas. Na Tabela 2 são apresentadas as empresas com os maiores valores de intangíveis em relação ao ativo total.

Tabela 2: Representatividade dos Ativos Intangíveis

\begin{tabular}{c|c|c|c}
\hline Empresa & Ativo total & Ativo intangível & Proporção de intangível em relação ao ativo total \\
\hline Sabesp & 39.546 .444 & 33.466 .132 & $84,62 \%$ \\
\hline Tpi - Triunfo & 4.589 .036 & 3.622 .071 & $78,93 \%$ \\
\hline Santos Brasil & 2.764 .690 & 1.847 .027 & $66,81 \%$ \\
\hline Qualicorp & 3.531 .358 & 2.259 .885 & $63,99 \%$ \\
\hline Kroton Educação & 18.667 .762 & 11.298 .889 & $60,53 \%$ \\
\hline Ecorodovias & 7.815 .758 & 4.539 .727 & $58,08 \%$ \\
\hline Senior Solution & 157.501 & 90.251 & $57,30 \%$ \\
\hline Copasa & 10.809 .992 & 6.135 .235 & $56,76 \%$ \\
\hline International Meal & 1.512 .424 & 838.102 & $55,41 \%$ \\
\hline CSU & 400.562 & 206.914 & $51,66 \%$ \\
\hline Restoque & 3.690 .947 & 1.889 .702 & $51,20 \%$ \\
\hline CCR & 30.612 .208 & 15.566 .428 & $50,85 \%$
\end{tabular}

Fonte: Dados da pesquisa

Nota-se que apenas $10,34 \%$ destas possuem mais de $50 \%$ de intangíveis em seu ativo total, ao mesmo tempo que dentre as 116 empresas analisadas percebeu-se também que mais de $70 \%$ delas, ou seja, 82 empresas têm menos de $25 \%$ de intangíveis declarados em seu ativo 
total. Para as demais os valores de intangíveis ficaram com representatividade entre $25 \%$ e $50 \%$ frente ao ativo total.

Mediante os dados obtidos relacionados ao checklist, observou-se que 3 perguntas, listadas no Quadro 2, receberam nota 0 em todas as empresas analisadas. Deste modo, elas foram consideradas não aplicáveis, tendo em vista a nulidade total nas respostas obtidas, para não comprometer a pontuação final de cada empresa, nem distorcer a análise realizada. Critério este utilizado por Silva, Ferreira e Maragno (2017), em que 6 perguntas do checklist analisado por eles recebeu nota 0 em todas as empresas analisadas e foram consideradas como não aplicáveis, sendo excluídos dos critérios determinantes do nível de evidenciação dos ativos tratados no artigo. Os itens excluídos dos critérios na determinação do nível de evidenciação desta pesquisa são apresentados na Tabela 3.

Tabela 3: Perguntas excluídas por obterem respostas nulas

\begin{tabular}{c|c}
\hline 16 & $\begin{array}{r}\text { Divulgou o valor justo inicialmente reconhecido dos ativos intangíveis adquiridos por meio de } \\
\text { subvenção ou assistência governamentais? }\end{array}$ \\
\hline 17 & $\begin{array}{r}\text { Divulgou o valor contábil inicialmente reconhecido dos ativos intangíveis adquiridos por meio de } \\
\text { subvenção ou assistência governamentais? }\end{array}$ \\
\hline 18 & $\begin{array}{r}\text { Divulgou se os ativos intangíveis adquiridos por meio de subvenção ou assistência governamentais } \\
\text { são mensurados, após o reconhecimento, pelo método de custo ou reavaliação? }\end{array}$ \\
\hline
\end{tabular}

Fonte: Dados da pesquisa

Ao analisar as empresas agrupadas por setor, notou-se que dentre as 21 perguntas restantes do checklist, o setor que mais evidenciou itens alcançando um percentual de evidenciação de $80,48 \%$ foi o setor de Bens Industriais, com uma média de 16,90 itens respondidos dentre os 21 possíveis. Já, o setor que teve o menor nível de evidenciação foi o de Materiais Básicos obtendo um percentual de 58,33\%, de 12,25 itens respondidos, obtendo um índice médio de 70,61\% conforme a Tabela 4.

Tabela 4: Média de evidenciação por setor

\begin{tabular}{l|l|c}
\multicolumn{1}{c|}{ Setor } & Resposta obtida & Percentual de evidenciação \\
\hline Bens Industriais & $\mathbf{1 6 , 9 0}$ & $\mathbf{8 0 , 4 8 \%}$ \\
\hline Consumo Cíclico & 14,42 & $68,66 \%$ \\
\hline Consumo Não Cíclico & 12,46 & $59,34 \%$ \\
\hline Materiais Básicos & $\mathbf{1 2 , 2 5}$ & $\mathbf{5 8 , 3 3 \%}$ \\
\hline Petróleo, Gás e Biocombustíveis & 15,80 & $\mathbf{7 5 , 2 4 \%}$ \\
\hline Saúde & 15,64 & $\mathbf{7 4 , 4 6 \%}$ \\
\hline Tecnologia e Telecomunicação & 15,60 & $\mathbf{7 4 , 2 9 \%}$ \\
\hline Utilidade Pública & 15,73 & $\mathbf{7 4 , 8 9 \%}$ \\
\hline
\end{tabular}

Fonte: Dados da pesquisa

Em comparação com o estudo realizado por Moura e Varela (2014) notou-se que o índice médio de evidenciação por setor de fato cresceu, visto que no estudo verificou-se que o maior índice encontrado foi o equivalente a $90 \%$ do setor de Tecnologia da informação, sendo este o maior índice encontrado na época, já o menor índice verificado foi o setor de Materiais Básicos com o índice de $60 \%$, enquanto que a média de evidenciação do estudo realizado em 2014 foi de 69\%. Além disto, verifica-se na Tabela 5, que nenhum dos itens pesquisados obteve $100 \%$ de evidenciação, revelando dubiedade na interpretação das normas para posterior divulgação, percebeu-se ainda uma média de evidenciação 14,82, dentre os 21 itens analisados nas notas explicativas das 116 empresas estudadas, gerando um percentual médio de evidenciação de $70,61 \%$ dos itens analisados. 
Tabela 5: Nível de evidenciação por questão analisada

\begin{tabular}{|c|c|c|c|c|c|}
\hline & $\begin{array}{l}\text { Perguntas para Identificar o Nível de Evidenciação dos Ativos } \\
\text { Intangíveis }\end{array}$ & $\mathbf{N}$ & Evidenciado & $\begin{array}{c}\text { \% de } \\
\text { Evidenciação }\end{array}$ & $\begin{array}{l}\text { Média de } \\
\text { evidenciação }\end{array}$ \\
\hline 1 & Divulgou informações sobre intangíveis separados em classes? & 116 & 108 & $93,10 \%$ & \multirow{21}{*}{$70,61 \%$} \\
\hline 2 & Divulgou se os intangíveis são de vida útil definida ou indefinida? & 116 & 111 & $95,69 \%$ & \\
\hline 3 & $\begin{array}{l}\text { Divulgou os motivos que fundamentam e os fatores mais } \\
\text { importantes que levaram à definição da vida útil definida ou } \\
\text { indefinida do intangível? }\end{array}$ & 116 & 103 & $88,79 \%$ & \\
\hline 4 & $\begin{array}{l}\text { Divulgou informações sobre os prazos de vida útil ou as taxas de } \\
\text { amortização utilizadas? }\end{array}$ & 116 & 99 & $85,34 \%$ & \\
\hline 5 & $\begin{array}{c}\text { Divulgou o valor contábil bruto da classe de intangível no início do } \\
\text { período? }\end{array}$ & 116 & 105 & $90,52 \%$ & \\
\hline 6 & $\begin{array}{l}\text { Divulgou o valor contábil bruto da classe de intangível no final do } \\
\text { período? }\end{array}$ & 116 & 105 & $90,52 \%$ & \\
\hline 7 & $\begin{array}{c}\text { Divulgou o valor contábil de ativos intangíveis cuja titularidade é } \\
\text { restrita? }\end{array}$ & 116 & 49 & $42,24 \%$ & \\
\hline 8 & $\begin{array}{c}\text { Divulgou o valor contábil de ativos intangíveis oferecidos como } \\
\text { garantia de obrigações? }\end{array}$ & 116 & 9 & $7,76 \%$ & \\
\hline 9 & $\begin{array}{l}\text { Divulgou o valor dos compromissos contratuais advindos da } \\
\text { aquisição de ativos intangíveis? }\end{array}$ & 116 & 93 & $80,17 \%$ & \\
\hline $\begin{array}{l}1 \\
0\end{array}$ & $\begin{array}{l}\text { Divulgou o valor contábil da amortização acumulada no início do } \\
\text { período? }\end{array}$ & 116 & 103 & $88,79 \%$ & \\
\hline $\begin{array}{l}1 \\
1\end{array}$ & Divulgou o valor contábil da amortização do período? & 116 & 99 & $85,34 \%$ & \\
\hline $\begin{array}{l}1 \\
2\end{array}$ & $\begin{array}{l}\text { Divulgou o valor contábil da amortização acumulada no final do } \\
\text { período? }\end{array}$ & 116 & 103 & $88,79 \%$ & \\
\hline $\begin{array}{l}1 \\
3\end{array}$ & $\begin{array}{l}\text { Divulgou os métodos de amortização utilizados para ativos } \\
\text { intangíveis com vida útil definida? }\end{array}$ & 116 & 104 & $89,66 \%$ & \\
\hline $\begin{array}{l}1 \\
4\end{array}$ & $\begin{array}{l}\text { Divulgou a rubrica da demonstração de resultado em que qualquer } \\
\text { amortização de ativo intangível foi incluída? }\end{array}$ & 116 & 98 & $84,48 \%$ & \\
\hline $\begin{array}{l}1 \\
5\end{array}$ & $\begin{array}{c}\text { Divulgou de forma separada o valor contábil das adições que foram } \\
\text { geradas por desenvolvimento interno e as adquiridas, bem como as } \\
\text { adquiridas por meio de uma combinação de negócios? }\end{array}$ & 116 & 58 & $50,00 \%$ & \\
\hline $\begin{array}{l}1 \\
6\end{array}$ & $\begin{array}{c}\text { Divulgou o valor contábil dos ativos classificados como mantidos } \\
\text { para venda ou incluídos em grupo de ativos classificados como } \\
\text { mantidos para venda e outras baixas? }\end{array}$ & 116 & 43 & $37,07 \%$ & \\
\hline $\begin{array}{l}1 \\
7\end{array}$ & Divulgou a data efetiva da reavaliação do intangível? & 116 & 9 & $7,76 \%$ & \\
\hline $\begin{array}{l}1 \\
8\end{array}$ & $\begin{array}{l}\text { Divulgou o saldo da reavaliação, relacionada aos ativos intangíveis, } \\
\text { no início e no final do período? }\end{array}$ & 116 & 9 & $7,76 \%$ & \\
\hline $\begin{array}{l}1 \\
9\end{array}$ & $\begin{array}{l}\text { Divulgou informações sobre a realização ou não do teste de } \\
\text { Impairment, de acordo com o Pronunciamento Técnico CPC } 01 \text { - } \\
\text { Redução ao Valor Recuperável de Ativos? }\end{array}$ & 116 & 115 & $99,14 \%$ & \\
\hline $\begin{array}{l}2 \\
0\end{array}$ & $\begin{array}{l}\text { Divulgou o valor das provisões de perdas, reconhecidas no } \\
\text { resultado do período, de acordo com o Pronunciamento Técnico } \\
\text { CPC } 01 \text { - Redução ao Valor Recuperável de Ativos? }\end{array}$ & 116 & 95 & $81,90 \%$ & \\
\hline $\begin{array}{l}2 \\
1\end{array}$ & $\begin{array}{l}\text { Divulgou o valor das reversões de perdas, reconhecidas no } \\
\text { resultado do período, de acordo com o Pronunciamento Técnico } \\
\text { CPC } 01 \text { - Redução ao Valor Recuperável de Ativos? }\end{array}$ & 116 & 102 & $87,93 \%$ & \\
\hline
\end{tabular}

Fonte: Dados da pesquisa

$\mathrm{Na}$ Tabela 5, nota-se que o item mais evidenciado foi o item 19, que trata sobre informações prestadas a respeito da divulgação de informações sobre a realização ou não do

RGO - Revista Gestão Organizacional, Chapecó, v. 13, n. 2, p. 142-161, maio/ago. 2020. 
teste de Impairment, de acordo com o Pronunciamento Técnico CPC 01 - Redução ao Valor Recuperável de Ativos, em comparação com o estudo de Silva, Ferreira e Maragno (2017), o item mais evidenciado foi o item 1 que havia recebido 100\% de evidenciação. Como já visto os resultados revelaram um índice médio de conformidade na população estudada de $70,61 \%$, sendo que o menor índice alcançado entre as empresas foi o percentual de $4,76 \%$ pelas empresas Direcional e Even Construtora e maior índice obtido o percentual de 87,50\% alcançado pela empresa Ecorodovias.

Em relação ao estudo de Silva, Ferreira e Maragno (2017) o item menos evidenciado foi o item 3 deste checklist com apenas $6,67 \%$ de evidenciação, muito diferente do valor encontrado nesta pesquisa, pois os itens $8,17,18$ foram os menos evidenciados, sendo que o item 8 trata da divulgação do valor contábil de ativos intangíveis oferecidos como garantia de obrigações, notou-se na pesquisa que poucas empresas se preocupam em evidenciar tais informações.

Já o item 17, que trata da divulgação da data efetiva da reavaliação do intangível, verificou-se que este foi outro quesito que as empresas não se preocuparam em informar ou ainda há de se considerar que talvez as empresas efetivamente não realizaram tal reavaliação e por este motivo não informaram, mas por consequência também não informaram a não necessidade de fazê-la.

Por fim, o item 18, dentre os menos evidenciados, que trata da Divulgação do valor das provisões de perdas, reconhecidas no resultado do período, de acordo com o Pronunciamento Técnico CPC 01 - Redução ao Valor Recuperável de Ativos, outra situação em que não se pode verificar na coleta dos dados, é se a não evidenciação se deu pelo fato de realmente não ser informado com a devida importância ou pelo fato de não haver necessidade de fazer tais provisões. Contudo, o fato é que não foram evidenciadas tais informações nas notas explicativas estudadas.

Os resultados vão ao encontro dos estudos realizados por Antunes, Da Silva e Saiki (2009), Crisóstomo, (2009), Ritta, Ensslin e Ronchi, (2010), Barcellos et al., (2011), Marques, Santos e Gouveia, (2011), Jacques, Rasia e Ott, (2012), Santos et al., (2012), Moura e Varela, (2014), Lopes et al., (2014), Lima et al., (2015), Silva, Ferreira e Maragno, (2017), Labidi e Gajewski (2019) e Sharma e Kaur (2019), que analisaram a evidenciação dos ativos intangíveis por meio de checklist. Percebe-se uma melhora no percentual de evidenciação o que demonstra que as empresas têm intenção de atender as normas pertinentes, mas, que ainda pairam dificuldades para a completa adequação.

Na sequência, a Tabela 6 demonstra o nível de evidenciação encontrado na pesquisa, destacando que a maioria das empresas estudadas estão em um nível considerado alto de evidenciação dos ativos intangíveis, considerando o percentual de 53,45\% destas.

Tabela 6: Nível de Evidenciação dos Ativos Intangíveis

\begin{tabular}{c|c|c|c|c}
\hline $\begin{array}{c}\text { Pontuação obtida por } \\
\text { empresas em \% }\end{array}$ & Nível de evidenciação & $\begin{array}{c}\text { Total de } \\
\text { empresas }\end{array}$ & $\begin{array}{c}\text { Número de } \\
\text { empresas }\end{array}$ & $\begin{array}{c}\text { \% de empresas por } \\
\text { nível de evidenciação }\end{array}$ \\
\hline \hline 0 a 25\% & Baixo & 116 & 9 & $7,76 \%$ \\
\hline 25,01 a 50\% & Médio/baixo & 116 & 4 & $3,45 \%$ \\
\hline 50,01 a 75\% & Médio/alto & 116 & 41 & $35,34 \%$ \\
\hline 75,01 a 100\% & Alto & 116 & 62 & $53,45 \%$ \\
\hline
\end{tabular}

Fonte: Dados da pesquisa

Ainda na Tabela 6 pode-se verificar que 35,54\% das empresas estão no nível considerado médio/alto, ou seja, mais de $88 \%$ das empresas estão demonstrando que tem buscado divulgar em suas demonstrações as informações em conformidade com as normas

RGO - Revista Gestão Organizacional, Chapecó, v. 13, n. 2, p. 142-161, maio/ago. 2020. 
do CPC 04 (R1) (2011). Enquanto aproximadamente 12\% das empresas estão num nível considerado baixo ou médio/baixo, demonstrando que elas não conseguiram adequar-se as normas estabelecidas pelo CPC 04 (R1) (2011). Estudos demonstram que as empresas possuem oscilação de percentual de evidenciação dos ativos intangíveis e ainda inferem que se estas mantivessem uma constante evidenciação seria benéfico para elas (LABIDI; GAJEWSKI, 2019; LIM; MACIAS; MOELLER, 2019; SHARMA; KAUR, 2019).

Silva, Ferreira e Maragno (2017), em estudo similar, encontraram que o nível de evidenciação considerado baixo na amostra estudada foi de $6,7 \%$, menor que o percentual encontrado nesta pesquisa, já para o nível médio/baixo o percentual encontrado foi de $13,3 \%$, maior que o obtido nesta pesquisa, enquanto que no nível médio/alto foi identificado o percentual de $60 \%$ da amostra que atenderam a mais e $50 \%$ dos itens analisados e para o nível alto apenas $20 \%$ da amostra obteve um percentual considerado alto, indicando que em comparação com os resultados obtidos houve uma melhora no nível de evidenciação. Ou seja, apesar da proporção dos ativos intangíveis estarem em ascensão nas empresas, a grande maioria delas não os evidencia nos seus demonstrativos financeiros ou em outros relatórios. Considerando que estes podem refletir impactos positivos nos desempenho da empresa (HAJl; GHAZALI, 2019; LIM; MACIAS; MOELLER, 2019).

\section{CONSIDERAÇÕES FINAIS}

Uma das questões debatidas de forma recorrente nas pesquisas acadêmicas ou nas discussões contábeis, é o tratamento dado aos intangíveis pelas empresas. Não existe um consenso, mas sim normas que orientam como proceder seu registro. Tal fato impulsiona a realização de pesquisas que buscam apurar como as empresas e os profissionais contábeis estão fazendo o registro dos ativos intangíveis nas demonstrações contábeis e nos relatórios.

A presente pesquisa teve por objetivo verificar o nível de evidenciação dos ativos intangíveis das empresas listadas no segmento Novo Mercado da B3 em conformidade com as normas determinadas no CPC 04 (R1), por meio de um índice de evidenciação elaborado com base no CPC 04 (R1). Os resultados revelaram um índice médio de conformidade na população estudada de $70,61 \%$, tendo como menor índice alcançado entre as empresas o percentual de 4,76\% pelas empresas Direcional e Even Construtora e maior índice obtido o percentual de $87,50 \%$ alcançado pela empresa Ecorodovias.

Ao verificar a representatividade dos ativos intangíveis frente ao ativo total das empresas, notou-se que apenas $10,34 \%$ das mesmas possuem mais de $50 \%$ de intangíveis em seu ativo total. Também foi verificado que mais de $70 \%$ delas, ou seja, 82 empresas têm menos de $25 \%$ de intangíveis registrados em seu ativo total. Assim as demais empresas tiveram seus valores de ativos intangíveis entre $25 \%$ e $50 \%$ de representatividade frente seu ativo total.

Ainda em análise realizada por setor, verificou-se que dentre perguntas estudadas, o setor que mais evidenciou itens em conformidade com o checklist estudado foi o setor de Bens Industriais, obtendo um percentual de evidenciação de $80,48 \%$ e o setor que menos evidenciou foi o setor de Materiais Básicos obtendo um percentual de 58,33\%.

Ao averiguar a evidenciação por item analisado do checklist, constatou-se que nenhum dos itens obteve $100 \%$ de evidenciação, revelando uma possível dificuldade na interpretação e divulgação das informações contábeis relativas aos ativos intangíveis, consoante ao reportado por Domeneghetti e Meier, (2009). Também é importante destacar que as normas que orientam a sobre a evidenciação dos ativos intangíveis abrange todas as empresas estudadas, que estas são auditadas e possuem registro na CVM. Mesmo assim, não existe uma

RGO - Revista Gestão Organizacional, Chapecó, v. 13, n. 2, p. 142-161, maio/ago. 2020. 
efetiva fiscalização ou penalização pelo descumprimento de normas e legislação aplicável. Tal fato exposto, aliado a dificuldade de interpretação das normas, faz com que haja a opção pela não evidenciação dos ativos intangíveis pelas empresas, quando a complexidade de evidenciação destes pode acarretar custos de profissionais especializados e ainda aumento nos custos de honorários de auditoria.

Mesmo assim, concluiu-se que mais da metade das empresas pesquisadas enquadraram-se num nível considerado alto, indicado pelo percentual de 53,45\% alcançado na análise, também foi constatado que $35,54 \%$ das empresas estão num nível considerado médio/alto e que aproximadamente $12 \%$ das empresas estão num nível considerado baixo ou médio/baixo. Logo, os resultados contribuem para demonstrar que as empresas têm buscado evidenciar nas demonstrações contábeis informações em conformidade com o disposto no CPC 04 (R1) (2011), mesmo que não atingindo a totalidade do itens previstos no checklist, mas na medida do possível buscam evidenciar. Todavia, se faz necessário destacar que as empresas analisadas desenvolvem atividades diferentes e que por isto possuem ativos intangíveis segundo a atividade desenvolvida. Resultando assim em uma maior ou menor quantidade de evidenciação destes ativos nas demonstrações contábeis.

Considerando a relevância deste tema e contribuindo para debates em futuras pesquisas a respeito do reconhecimento e da evidenciação dos ativos intangíveis, sugere-se pesquisas que tratem da fiscalização do uso do CPC 04 (R1) (2011), se alguma empresa foi penalizada por não atender ao disposto na norma. Sobre opinião modificada e honorários de auditoria em empresas com quantidade representativa de ativos intangíveis frente a tangíveis. Também, as pesquisas centram-se nos ativos intangíveis e não abordam os passivos intangíveis presentes nas empresa. Ainda, sugere-se a ampliação deste em quantidade de anos e amostra.

\section{REFERÊNCIAS}

ANTUNES, M. T. P.; LEITE, R. S. Divulgação de informações sobre ativos intangíveis e sua utilidade para analistas de investimentos. Revista Universo Contábil, Blumenau, v. 4, n. 4, p. 22-38, 2008. DOI: http://dx.doi.org/10.4270/ruc.20084

ANTUNES, M. T. P.; SILVA, L. C. P.; SAIKI, T. G. Evidenciação dos ativos intangíveis (capital intelectual) por empresas brasileiras à luz da Lei 11.638/07. In: XVI Congresso Brasileiro de Custos. Fortaleza. Anais [...]. Associação Brasileira de Custos: Fortaleza, 2009. Disponível em: https://anaiscbc.emnuvens.com.br/anais/article/view/1033. Acesso em: 29 abr. 2020.

ALMEIDA, V. R.; JORDÃO, R. V. D. Análise dos efeitos do capital intelectual na lucratividade das empresas brasileiras. Revista Universo Contábil, Blumenau, p. 104-126, mar. 2018. DOI: http://dx.doi.org/10.4270/ruc.2017428.

BARCELLOS, M.; ENSSLIN, S. R.; SILVA, H. A. S.; REINA, D. R. M. Aderência ao CPC 04 (R1): existe relação ao grau de intangibilidade? In: II Congresso Nacional e Administração e Ciências Contábeis, Rio de Janeiro. Anais [...]. Rio de Janeiro, 2011. Disponível em: http://adcont.net/index.php/adcont/adcont2011/paper/view/357. Acesso em: 29 abr. 2020.

BARSCH, L. S.; SOUZA, M. M.; Características da evidenciação da fase de pesquisa e desenvolvimento de ativos intangíveis nas companhias de capital aberto brasileiras. Revista 
de Contabilidade da UFBA, Salvador, v. 12, n. 1, p. 137-156, 2018.

DOI: http://dx.doi.org/10.9771/rc-ufba.v12i1.21422

BM\&FBOVESPA. BM\&FBOVESPA. Disponível em:

<http://www.bmfbovespa.com.br/pt_br/produtos/listados-a-vista-e-derivativos/rendavariavel/empresas-listadas.htm>. Acesso em: 10 nov. 2015.

BRASIL. Lei 11.638 de 28 de dezembro de 2007. Altera e revoga dispositivos [...]. DIÁRIO OFICIAL DA UNIÃO REPÚBLICA DO BRASIL, Brasília, DF, 28 dez. 2007. Disponível em: <http://www.planalto.gov.br/ccivil_03/_ato2007-2010/2007/Lei/L11638.htm>. Acesso em: 10 nov. de 2015.

BRIZOLLA, M. M. B.; TURRA, S. Efeitos do capital intelectual sobre o desempenho financeiro em companhias de capital aberto. Revista Eletrônica de Administração e Turismo-ReAT, Pelotas, v. 6, n. 3, p. 577-594, 2015. DOI: http://dx.doi.org/10.15210/reat.v6i3.5222

CALDAS, M. A. F.; CARVALHAL, R. L. Intangíveis e o valor da empresa - O caso da Vale. In: Simpósio Brasileiro de Pesquisa Operacional, 43., Ubatuba. Anais [...]. Ubatuba: UEM, 2011. Disponível em: din.uem.br/ ademir/sbpo/sbpo2011/pdf/87232.pdf. Acesso em: 29 abr. 2020.

CALLADO, A. L. C.; SILVA, A. R. Características da produção científica associada à intangibilidade e desempenho econômico-financeiro sob a perspectiva de redes sociais. Desafio Online, Campo Grande, v. 6, n. 1, p. 122-140, 2018.

CAVALCANTI, J. M. M.; AMARAL, H. F.; CORREIA, L. F.; LOUZADA, L. C. Proposta de convergência teórica das perspectivas das finanças e da contabilidade na avaliação de ativos intangíveis. Revista Universo Contábil, Blumenau, p. 177-193, mar. 2018. DOI: http://dx.doi.org/10.4270/ruc.2017431.

CHANDER, S.; MEHRA, V. A study on intangible assets disclosure: An evidence from Indian companies. Intangible capital, v. 7, n. 1, p. 1-30, 2011. DOI:10.3926/ic.2011.v1n7.p1-30.

CPC - COMITÊ DE PRONUNCIAMENTOS CONTÁBEIS. Pronunciamento Conceitual Básico. CPC 00 (R2) - Estrutura Conceitual para Elaboração e Divulgação de Relatório Contábil-Financeiro. 2019. Disponível em: http://static.cpc.aatb.com.br/Documentos/573_CPC00(R2).pdf Acesso em: 28 abr. 2020.

CPC - COMITÊ DE PRONUNCIAMENTOS CONTÁBEIS. Pronunciamento Técnico. CPC 04 (R1) Ativos Intangíveis. 2010. Disponível em:

<http://www.cpc.org.br/pronunciamentosIndex.php> Acesso em: 10 nov. 2015.

CRISÓSTOMO, V. L. Ativos intangíveis: estudo comparativo dos critérios de reconhecimento, mensuração e evidenciação adotados no Brasil e em outros países. Journal of Accounting, Management and Governance, v. 12, n. 1, maio. 2009. 
CUNHA, A. G.; SOUZA, A. A.; SANTANA, L. F.; MAGALHÃES, V. G.; PELEGRINI, V. S.; MALAQUIAS, R. F. Evidenciação de ativos intangíveis: um estudo com empresas brasileiras. Revista Mineira de Contabilidade, Belo Horizonte, v. 3, n. 43, p. 21-29, jul-set. 2011.

CVM - COMISSÃO DE VALORES MOBILIÁRIOS. Deliberação CVM № 644, de 2 de dezembro de 2010. Aprova o Pronunciamento Técnico CPC 04(R1) do Comitê de Pronunciamentos Contábeis - CPC sobre ativo intangível. Disponível em:

http://www.cvm.gov.br/export/sites/cvm/legislacao/deliberacoes/anexos/0600/deli644.pdf Acesso em: 29 abr. de 2020.

DOMENEGHETTI, D.; MEIER, R. Ativos intangíveis - o real valor das empresas. São Paulo: Campus, 2009.

ELOY J. C. C.; SOUZA M. M.; Reconhecimento dos ativos intangíveis nas combinações de negócios: uma análise nas características das companhias de capital aberto brasileiras no período entre 2012 e 2014. Revista de Contabilidade da UFBA, Salvador, v. 12, n. 1, p. 116136, jan-abr., 2018. DOI: http://dx.doi.org/10.9771/rc-ufba.v12i1.21649

SILVA FILHO, L. L.; LAGIOIA, U. C. T.; CARLOS FILHO, F. A.; ARAÚJO, J. G.; LEMOS, L. V. Um estudo sobre o reflexo no reconhecimento dos ativos intangíveis após a adoção das normas internacionais de contabilidade nas empresas brasileiras listadas na BM\&FBOVESPA. Revista Contexto, Porto Alegre, v. 14, n. 27, p. 55-69, maio/ago. 2014.

FREIRE, M. D. M.; MACHADO M. R.; MACHADO, L. S.; SOUZA, E. S.; OLIVEIRA, J. J. Aderência às normas internacionais de contabilidade pelas empresas brasileiras. Revista de

Contabilidade e Organizações, São Paulo, v. 6 n. 15. p. 3-22, 2012.

DOI: https://doi.org/10.11606/rco.v6i15.52654

FREIRE, M. M. A.; ALBUQUERQUE FILHO, A. R.; MACEDO, F. F. R. R.; Intangibilidade, competitividade e governança corporativa: estudo nas companhias listadas na Brasil Bolsa Balcão (B3). In: Congresso ANPCONT, 12., João Pessoa. Anais [...]. João Pessoa: AnpCont, 2018. Disponível em: <http://www.anpcont.org.br/pdf/2018_CUE520.pdf>. Acesso em: 19 de mai. 2020.

JACQUES, F. V. S., RASIA, K. A., OTT, E. A evidenciação do ativo intangível em notas explicativas por empresas de capital aberto integrantes da BOVESPA. Revista Espacios, Caracas, v. 33, n. 3, p. 13, 2012.

JANOSEVIĆ, S.; DZENOPOLAC, V. An investigation of intellectual capital influence on financial performance of top Serbian exporters. Ekonomika Preduzeća, v. 60, n. 7-8, p. 329342, 2012.

JOSEPH, G. P. A.; GONÇALVES-DIAS S. L. F.; FELSBERG A. V.; IGARI A. T. Responsabilidade social corporativa e índices de sustentabilidade: um estudo dos ativos tangíveis e intangíveis à luz da visão baseada em recursos. Revista de Gestão Social e Ambiental - RGSA, São Paulo, v. 12, n. 1, p. 73-88, jan./abr. 2018. DOI: http://dx.doi.org/10.24857/rgsa.v12i1.1304 
HAJI, A. A.; GHAZALI, N. A. M. The role of intangible assets and liabilities in firm performance: empirical evidence. Journal of Applied Accounting Research, v. 19, n. 1, p. 4259. 2018. DOI: https://doi.org/10.1108/JAAR-12-2015-0108

KAYO, E. K. A estrutura de capital e o risco das empresas tangível e intangível intensivas: uma contribuição ao estudo da valoração de empresas. 2002. 110f. Tese (Doutorado em Administração) - Departamento de Administração da Faculdade de Economia, Administração e Contabilidade da USP. São Paulo, 2002. Disponível em:

<www.teses.usp.br/teses/disponiveis/12/12139/tde-05032003.../pt-br.php >. Acesso em: 29 de abr. 2020.

LABIDI, M.; GAJEWSKI, J. F. Does increased disclosure of intangible assets enhance liquidity around new equity offerings? Research in International Business and Finance, v. 48, p. 426437, 2019. DOI: https://doi.org/10.1016/j.ribaf.2019.01.009

LEMES, S.; CARVALHO, L. N. Contabilidade internacional para graduação. São Paulo: Atlas, 2010.

LEV, B. Intangibles: management, measurement and reporting. Washington: Brookings, 2001.

LIM, S.C.; MACIAS, A.J.; MOELLER, T. Ativos intangíveis e estrutura de capital. 2019. DOI: http://dx.doi.org/10.2139/ssrn.2514551

LIMA, M. D. X.; PRAZERES, R. V.; ARAÚJO, J. G. N.; ARAÚJO, J. G.; OLIVEIRA, M. F. J. Análise do nível de divulgação dos ativos intangíveis e imobilizados das companhias do setor de construção e transporte da BM\&FBOVESPA. In: Congresso Iniciação Científica em Contabilidade - USP, 12., São Paulo. Anais [...]. São Paulo: USP, 2015. Disponível em: https://congressousp.fipecafi.org/anais/artigos152015/85.pdf. Acesso em: 29 de abr. de 2020.

LOPES, L. C.; ALVES, N. M.; SILVA FILHO, L. L.; MONTEIRO, J. A. M.; LAGIOIA, U. C. T.; CORDEIRO, P. C. Evidenciação das informações dos ativos intangíveis: um estudo sobre o nível de aderência das companhias brasileiras do setor de bens industriais listadas na bolsa de valores do Brasil ao CPC 04. Qualitas Revista Eletrônica, Campina Grande, v. 15, n. 1, jun. 2014. DOI: http://dx.doi.org/10.18391/qualitas.v15i1.1911.

MAGRO, C. B. D.; SILVA, A.; PADILHA, D.; KLANN, R. C. Relevância dos ativos intangíveis em empresas de alta e baixa tecnologia. Nova Economia, v. 27 n. 3 p. 609-640, 2017. DOI: https://doi.org/10.1590/0103-6351/3214

MARQUES, J. A. V. C.; SANTOS, R. F.; GOUVEIA, V. A. L. Análise da evidenciação do ativo intangível nas demonstrações contábeis. Pensar Contábil, Rio de Janeiro, v. 13, n. 52, 2011.

MELLO, J. A. V. B.; GONÇALVES, F. M.; CORREIA, F. D. S.; MOURÃO, H. M. Percepções sobre valoração dos ativos intangíveis em clubes de futebol do Rio De Janeiro. Revista de 
Administração de Roraima - RARR, Boa Vista, v. 7, n. 2, p. 331-347, fev. 2018. DOI: http://dx.doi.org/10.18227/2237-8057rarr.v7i2.3989.

MENESES, A. F.; PONTE, V. M. R.; MAPURUNGA, P. V. R. Determinantes do nível de disclosure de ativos intangíveis em empresas brasileiras. Revista Base (Administração e Contabilidade) da UNISINOS, São Leopoldo, v. 10, n. 2, p. 142-153, 2013.

MORAES, J. P. S. C.; CARVALHO, L. Relação entre os ativos intangíveis e o desempenho econômico das empresas que compõem o índice IBRX 100 - Índice Brasil. In: SEMEAD Seminários em Administração, 20., São Paulo. Anais [...]. São Paulo: USP, 2017. Disponível em: <http://login.semead.com.br/20semead/arquivos/1269.pdf>. Acesso em: 27 de jun. 2018.

MOURA, G. D. DALLABONA, L. F. FANK, O. L. VARELA, P. S. Boas Práticas de Governança Corporativa e Evidenciação Obrigatória dos Ativos Intangíveis. In: Congresso USP de Controladoria e Contabilidade, 11., São Paulo. Anais [...]. São Paulo: USP, 2011. Disponível em: <http://www.congressousp.fipecafi.org/web/artigos112011/507.pdf>. Acesso em: 9 mar. 2016.

MOURA, G. D.; VARELA, P. S. Análise da conformidade das informações divulgadas sobre ativos intangíveis em empresas listadas na BM\&FBOVESPA. Revista de Administração, Contabilidade e Economia, Joaçaba, v. 13, n. 2, p. 637-662, 2014.

DOI: $10.18593 /$ race.v13i2.2659

MOURA, G. D.; VARELA, P. S.; BEUREN, I. M. Conformidade do disclosure obrigatório dos ativos intangíveis e práticas de governança corporativa. Revista de Administração Mackenzie, São Paulo, v. 15, n. 5, 2014. DOI: https://doi.org/10.1590/167869712014/administracao.v15n5p140-170

MOURA, G. D.; FANK, O. L.; RAUSCH, R. B. Evidenciação do capital intelectual pelas empresas do setor de telefonia fixa listadas na bolsa de valores, mercadorias e futuros BM\&FBOVESPA. Revista de Administração da Unimep, Piracicaba, v. 12, n. 2, p. 1-20, 2014. DOI: 10.15600/1679-5350/rau.v12n2p1-20

MUHAMMADI, A. H., AHMED, Z., HABIB, A. Multinational transfer pricing of intangible assets: Indonesian tax auditors' perspectives. Asian Review of Accounting, v. 24, n. 3, p. 313-337, 2016. DOI: https://doi.org/10.1108/ARA-10-2014-0112.

ORO, I. M.; KLANN, R. C. Disclosure obrigatório de ativos intangíveis das companhias listadas nos níveis de governança corporativa da BM\&FBOVESPA. Pensar Contábil, Rio de Janeiro, v. 17, n. 62, 2015.

PIONTKEWICZ, R.; FREITAS, M. C. D. Pré-requisitos necessários para um sistema de informação contábil realizar a gestão do capital intelectual. Revista Tecnologia e Sociedade. v. 14, n. 31, p. 171-188, mai./ago. 2018. DOI: https://doi.org/10.3895/rts.v14n31.7023 
PUNTILLO, P. Intellectual capital and business performance. Evidence from Italian banking industry. Electronic Journal of Corporate Finance, V. 4, n. 12, p. 97-115, 2009.

RECH, J. O.; SCHNORRENBERGER, D.; LUNKES, R. J. A análise comportamental dos Ativos Intangíveis: Um estudo nas COMPANHIAS da BM\&FBOVESPA. Revista Contabilidade e Controladoria, v. 4, n. 2, 2012. DOI: http://dx.doi.org/10.5380/rcc.v4i2.26983

RITTA, C. O.; CUNHA, L. C.; KLANN, R. C.; Um Estudo sobre causalidade entre ativos intangíveis e desempenho econômico de empresas (2010 - 2014). Revista de Contabilidade do Mestrado em Ciências Contábeis da UERJ, Rio de Janeiro, v. 22, n. 2, p. 92 - p. 107, 2017.

RITTA, C. O.; ENSSLIN, S. R.; RONCHI, S. H. A Evidenciação dos ativos intangíveis nas empresas brasileiras: empresas que apresentaram informações financeiras à Bolsa De Valores de São Paulo e Nova York Em 2006 e 2007. Revista Eletrônica de Ciência Administrativa, v. 9, n. 1, p. 62, 2010. DOI: https://doi.org/10.5329/RECADM.20100901005

SAHUT, J.-M.; BOULERNE, S.; TEULON, F. Do IFRS provide better information about intangibles in Europe? Review of Accounting and Finance, v. 10, n. 3, p. 267-290. 2011. https://doi.org/10.1108/14757701111155798

SANTOS, A. V. F; XIMENES, C. G.; GALLON, A. V.; LUCA, M. M. M. Evidenciação de ativos intangíveis nas empresas industriais mais inovadoras segundo classificação do Índice Brasil de Inovação (IBI). Revista ADM. MADE, Rio de Janeiro, v. 16, n. 1, p. 1-23, 2012.

SGODA, C.; FREITAG, V. C. Percepções sobre o Registro da Marca. Revista ADMpg Gestão Estratégica. v. 8, n. 2, 14 dez. 2015.

SHARMA, K.; KAUR, M. Intangible assets: reporting practices and hidden value measurement. Research journal of social sciences, v. 10, n. 1, 2019.

SILVA, N. C., FERREIRA, D. D. M., MARAGNO, L. M. D. A evidenciação de ativos intangíveis nas empresas do setor de saúde da B3. In: Congresso Unisinos de Controladoria e Finanças, 4., São Leopoldo. Anais [...]. São Leopoldo: Unisinos, 2017. Disponível em: <https://repositorio.ufsc.br/handle/123456789/183684>. Acesso em: 27 de jun. 2018.

VENTURA, A. K.; ROVER, S. Nível de comparabilidade dos ativos intangíveis das companhias brasileiras do setor de energia elétrica listadas na Bm\&Fbovespa. In: II Congresso de Gestão e Controladoria (COGECONT), Chapecó. Anais [...]. Chapecó: Unochapecó, 2017. Disponível em: https://repositorio.ufsc.br/handle/123456789/183708. Acesso em: 29 de abr. 2020.

VISVANATHAN, G. Intangible assets on the balance sheet and audit fees. International Journal of Disclosure and Governance, v. 14, n. 3, p. 241-250, 2017. DOI:

https://doi.org/10.1057/s41310-017-0023-x 